Elvin M. Aliyev

DOI: $10.25045 /$ jpit.v06.i2.08

Institute for Space Research of Natural Resources, Baku, Azerbaijan

elvin.aliyev.m@gmail.com

\title{
GEOINFORMATION ANALYSIS OF REAL ESTATE OBJECTS ON THE BASIS OF HIGH-RESOLUTION AEROSPACE INFORMATION
}

The article investigates the possibilities of application of high resolution remote sensing data for the creating electronic cadastral database; it classifies topological errors on spatial data and defines correlation relations between them have been. In addition, the identification method of active areas in Real Estate Market is developed and comparative analysis of dynamic models based on different interpolation methods is carried out.

Keywords: geoinformation, remote sensing, ECD, shp, AZERSKY, GeoEye-1, IKONOS-2, panchromatic image, multispectral image.

\section{The objective and relevance of the study}

Modern state of urban infrastructure (ALS) requires the creation of Electronic Cadastral Database (ECD) in the Computer-Aided Design (CAD) and geographic information systems (GIS) platform through high resolution remote sensing data, which guarantees high accuracy of geometric indicators in drawing up the technical passports and cadastral plans, and serves to the regulation of property issues, as well. However, GIS and aerospace data are not used appropriately by the relevant bodies dealing with property issues yet. Lack of updated topographical plans in the certain range of time is one of the indicative factors of gaps in this area.

Therefore, serious problems come across in the legal registration and acquisition of real estate. In addition to the above-mentioned problems, topological errors and configuration violations that can be observed in the prescriptive documents presented to the citizens, which can be solved by means of innovative technologies and high resolution spatial data. In this regard, there is a need for new approaches to identify more advanced aspects of the digitalization process in the sphere of property issues in the near future. The data analysis defined the configuration violations in many areas, and this is explained by the lack of oversight system. The targets and conducted researches evidence that, establishment of ECD relied on high resolution spatial data and topographical plans over GIS should be mainstreamed in the near future. Mixed issues of areas referring to different properties should be completely eliminated both in conceptual and technological arena. The existence of pending problems, and still unsolved property issues within these problems require more drastic steps to be taken in this field.

Topological analysis of spatial data on the real estate with the use of high resolution aerospace data in ECD platform is of particular importance in drawing up cadastral plans and technical passports. In addition, modeling of real estate market is one of the vital issues. It is one of the incomplete topical issues in construction of huge real estate complexes, property market forecast, and allocating investments in the area. Solving the issues set forth envisages the application of GIS and high resolution aerospace data, as well as use of mathematical-statistical analysis methods. Topological errors containing the factors of different origins, as well as finding out the relations between the supervisory sequences taking into account multiple factors make necessary the application of mathematical-statistical methods. In this regard, besides GIS analysis methods, the application of mathematical-statistical methods should be widely highlighted in ECD, as well. It should be noted that different deterministic and geostatistic interpolation methods are used in the GIS analysis methods of the real estate market modeling. Complex study of such methods is of great importance for modeling of various thematic issues.

The article outlines the studies of ECD -based GIS analysis procedures and determines its contribution to the solution of various issues in following future studies:

- determining active areas in the real estate market for any territory; 
- conducting GIS analyzes of the various forms of property, digital mapping of objects and events;

- Geostatistical analysis of the spatial data within the specified time interval;

- creating of geographic information systems for different purposes etc.

Following issues were put forward in the article and have been resolved:

1. Exploration of the application opportunities of aerospace data with high spatial resolution in cadastral works.

2. Creation of the ECD for management of spatial objects in accordance with orthophoto plans based on aero shootings.

3. Classification of topological errors in the ECD and identifying correlation ties among them.

4. Elaboration of the method for defining the active areas in the real estate market, classification of the active areas in real estate market over studied area by the method.

5. Conduction of comparative analysis among the dynamic models of the real estate market based on interpolation methods which are available in geostatistical analyze module (Ordinary Kriging IDW, radial basis function method, global and local polynomial methods).

\section{The used materials}

High resolution aerospace data applied to the solution of the set issues have the following technical features (table 1):

$$
\text { GeoEye - } 1 \text { (Digital Globe) }
$$

Spatial resolution: $1.65 \mathrm{~m}$ (multi-spectral shooting); microns.

Spectral band: 0.45 - 0.51 microns; $0.51-0.58$ microns; 0.66 - 0.69 microns; $0.78-0.92$

Date of plan: 2010

\section{Orthophoto plans (aerial photography)}

$\begin{array}{llll}\text { Scale: } & 1: 1000 & 1: 5000 & 1: 5000 \\ \text { Spatial resolution: } & 11.0 \mathrm{~cm} & 25.0 \mathrm{~cm} & 30.0 \mathrm{~cm} \\ \text { Relief resolution: } & 10.0 \mathrm{~cm} & 35.0 \mathrm{~cm} & -------- \\ \text { Plan area }\left(\mathrm{km}^{2}\right): & 20000 & 42000 & ------- \\ \text { Date of plan: } & 2008 & 2008 & 2003\end{array}$

Technical features of orthophotos used in the creation of ECD

\begin{tabular}{|c|c|c|c|c|}
\hline $\begin{array}{c}\text { Initial data } \\
\text { (aerophoto) }\end{array}$ & $\begin{array}{c}\text { Spatial resolution } \\
(\mathrm{x}, \mathrm{y})\end{array}$ & $\begin{array}{c}\text { Relief resolution } \\
(\mathrm{z})\end{array}$ & Plan area $\left(\mathrm{km}^{2}\right)$ & $\begin{array}{c}\text { Date of plan, } \\
\text { year }\end{array}$ \\
\hline $\begin{array}{c}\text { Orthophoto } \\
\text { plans (1:1000) }\end{array}$ & $11,0 \mathrm{~cm}$ & $0,10-0,35 \mathrm{~m}$ & 20000 & 2008 \\
\hline $\begin{array}{c}\text { Orthophoto } \\
\text { plans (1:5000) }\end{array}$ & $25,0 \mathrm{~cm}$ & $1,7-3,0 \mathrm{~m}$ & 42000 & 2008 \\
\hline
\end{tabular}

\section{Problem-solution methods}

Currently, resolution of remote sensing (RS) data with high resolution is designed in $3.0-0.31$ $\mathrm{m}$, it defines various elements of the huge property complexes, as well as the real estate, which is of particular importance in GIS analysis. The development of large-scale maps and plans such as 1: 5000, 1: 2000 etc. is feasible with the use of high resolution RS data.

One of the most important issues facing in the creation of ECD is the development of large-scale orthophoto (Figure 1). It's designed to be used for the study of the status of real estate 
in the country, and for the verification of available registration documents. Initially, the areas are identified, which are necessary for the preparation of base maps. 1: 1000 and 1: 5000 scaled ortophoto plans have been developed for creation of Baku city's ECD (Figure 2) and the registration of property rights, and submitted to the territorial offices. Basic parameters of the high resolution optical-electronic systems to be applied to the property issues are reflected in Table 2 .

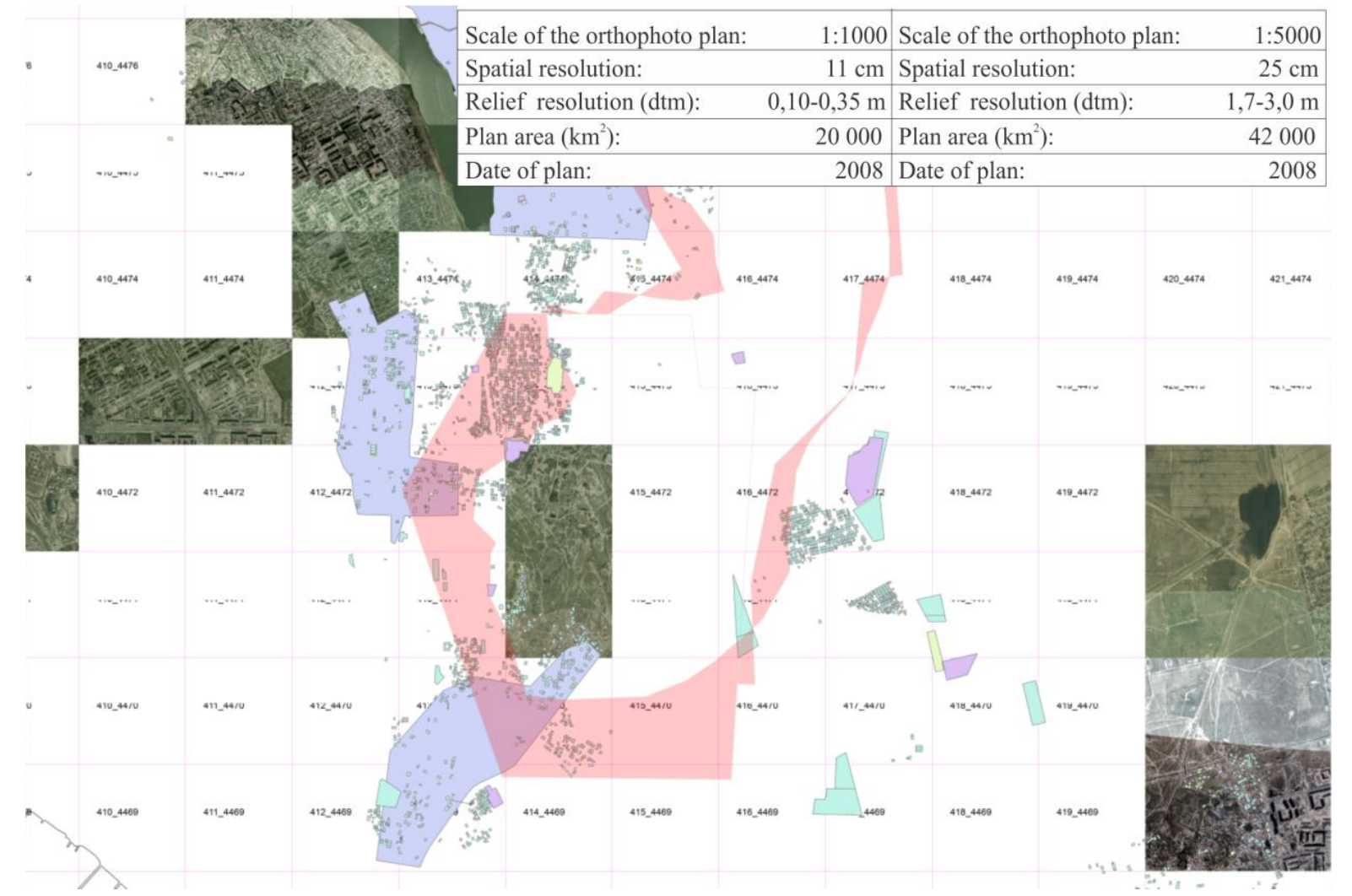

Figure 1. ECD of Surakhani district created on the basis of high spatial resolution orthophoto plans in the GIS platform

Note that, detection of illegal buildings do not require the use of high resolution data. However, the use of high spatial resolution RS data is necessary in specifying the geometric parameters of soils, determining coordinates, drawing up of technical passports and cadastral plans. GeoEye-1 (panchromatic $0.41 \mathrm{~m}$ ), GeoEye-2 (panchromatic $0.34 \mathrm{~m}$ ) and WorldView-2 (panchromatic $0.46 \mathrm{~m}$ ), WorldView-3 (panchromatic0.31 m) are considered RS data with the highest technical features in solutions of above-mentioned issues.

High resolution remote sensing data has an important role both in cadastral works, and in solution of the following issues:

- developing and updating 1: 2000 scaled digital topographic maps;

Table 2

Classification of high resolution optical-electronic systems applicable to property issues

\begin{tabular}{|c|c|c|c|c|}
\hline \multirow{2}{*}{ Satellites } & \multirow{2}{*}{ Country } & \multirow{2}{*}{ Date } & \multicolumn{2}{|c|}{ Spatial resolution, m } \\
\cline { 4 - 5 } & & & Panchromatic & Multi-spectral \\
\hline AZERSKY & Azerbaijan & 30.06 .14 & 1,5 & 6,0 \\
\hline IKONOS-2 & USA & 24.09 .99 & 1,0 & 4,0 \\
\hline QuickBird-2 & USA & 18.10 .01 & 0,6 & 2,4 \\
\hline OrbView-3 & USA & 26.06 .03 & 1,0 & 4,0 \\
\hline EROS-B & Israel & 01.03 .06 & 0,7 & - \\
\hline Pecypc-ДК1 & Russia & 15.06 .06 & 1,0 & 3,0 \\
\hline
\end{tabular}




\begin{tabular}{|c|c|c|c|c|}
\hline KOMPSAT-2 & Korea & 28.07 .06 & 1,0 & 4,0 \\
\hline Cartosat-2 & India & 10.01 .07 & 0,8 & - \\
\hline WorldView-1 & USA & 18.09 .07 & 0,5 & - \\
\hline Cartosat-2A & India & 28.04 .08 & 0,8 & - \\
\hline GeoEye-1 & USA & 08.10 .08 & 0,41 & 1,65 \\
\hline WorldView-2 & USA & 08.10 .09 & 0,46 & 1,8 \\
\hline Pleiades-1 & France & 2010 & 0,5 & 2,0 \\
\hline GeoEye-2 & USA & 2012 & 0,34 & 1,36 \\
\hline Pecypc-П1 & Russia & 25.06 .13 & $0,5-1$ & - \\
\hline WorldView-3 & USA & 13.08 .14 & 0,31 & 1,24 \\
\hline Pecypc-П2 & Russia & 26.12 .14 & 1,0 & $2-3$ \\
\hline
\end{tabular}

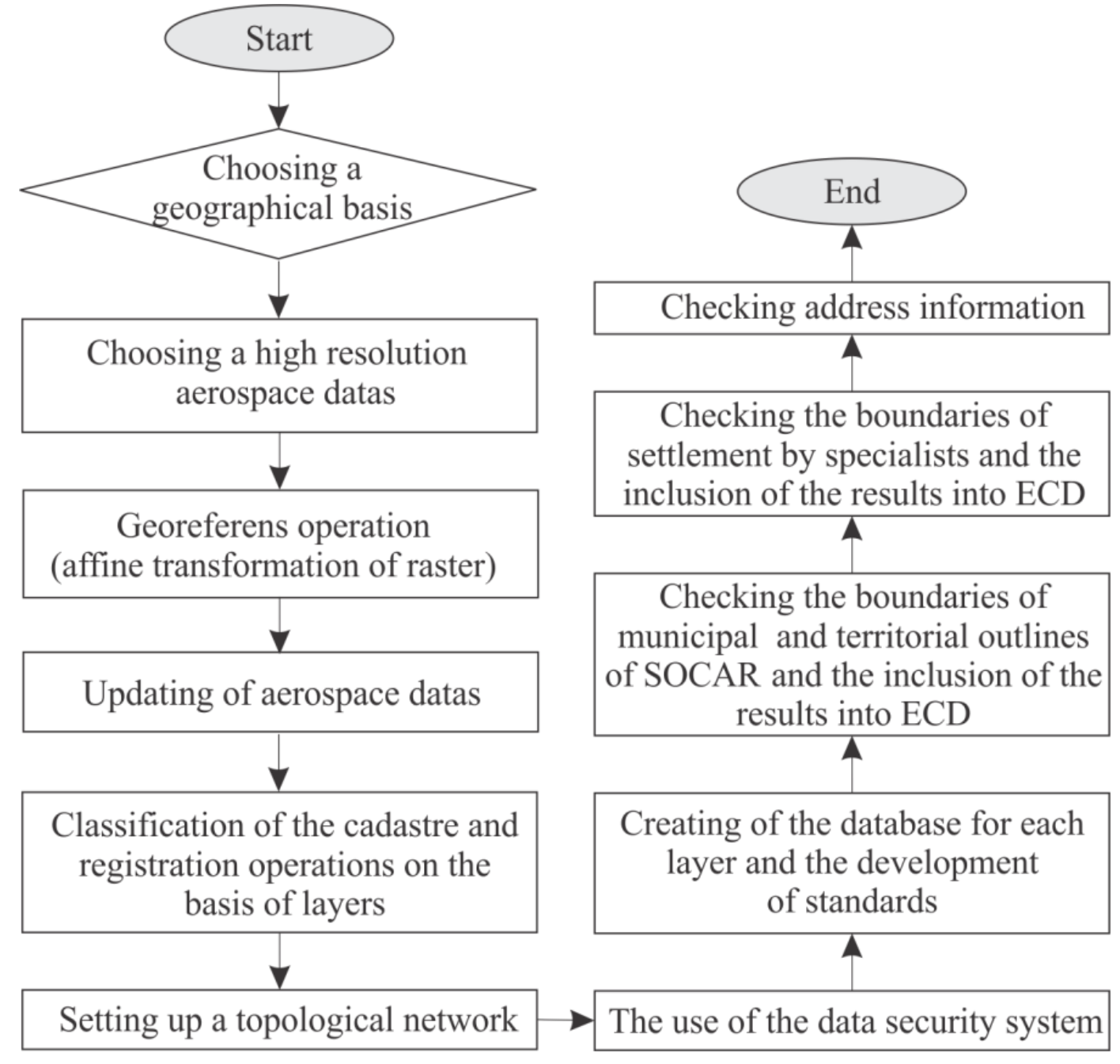

Figure 2. The procedural stages of GIS-based ECD formation

- Creating digital elevation model of high-resolution;

- Organizing the control on inventory and the construction of facilities;

- Creating multiple management systems,

- Planning cities and regions, evaluating;

- Modeling and visualization etc.

Recently, the evaluation of the dynamic impact of anthropogenous, endogenous and exogenous processes on the Earth through the traditional studies is not sufficient enough. 
Analyzing the objects and events, electronic mapping of dynamics of the anthropogenic impacts, developing other cartographic products with different subject-matter, and ultimately thorough study of our planet makes the application of remote sensing necessary. Remote sensing data provides not only the study of objects and events at remotely, without any contact, but also allows its thematic processing. Thematic processing of information obtained from the Earth's surface sensing records the changes of natural and manmade origin and provides quantitative and qualitative assessment. A number of linear and non-linear projecting works (oil, gas, main water lines, etc.), carrying out various cadastres etc. are resolved by using high resolution aerospace data obtained as a result of local shootings. It should be noted that, before, law resolution remote sensing data were not applied to the property issues. The development of science and technology, competitiveness criteria in this area pave the way to obtain high resolution remote sensing data. Topological analysis of the spatial data in ECD is conducted, as well as, geometric errors are identified and classified in the article. Detection of topological errors shows the inaccuracy of geometric indicators in the technical passports. In addition, intersecting outlines of areas connected with property violations in ECD are identified. As a result of analysis 90 errors are found in the technical passport (TP) layer, while this figure is 61 over 269 data in the distribution layer (Table 3). Amendment of the errors are carried out according to the orthophoto plans (Figure 3).

Table 3.

Monthly presentation of topological errors found on registered soils and on their spatial data

\begin{tabular}{|l|c|c|c|c|c|c|c|c|c|c|c|c|}
\hline Month & 1 & 2 & 3 & 4 & 5 & 6 & 7 & 8 & 9 & 10 & 11 & 12 \\
\hline Tp & 32 & 38 & 54 & 60 & 46 & 37 & 52 & 49 & 82 & 87 & 60 & 58 \\
\hline TP $_{\mathbf{x}}$ & 4 & 5 & 7 & 8 & 6 & 4 & 7 & 6 & 13 & 14 & 9 & 7 \\
\hline D & 17 & 18 & 15 & 20 & 25 & 22 & 19 & 23 & 29 & 24 & 29 & 28 \\
\hline $\mathbf{D}_{\mathbf{y}}$ & 3 & 4 & 5 & 3 & 5 & 4 & 6 & 7 & 5 & 6 & 7 & 6 \\
\hline
\end{tabular}

While creating ECD, municipal and settlement boundaries are specified based on existing lines both in the rural and cameral conditions, an electronic copy of the territorial outlines of SOCAR is obtained and included into ECD. In addition, the address information are specified and common standards are developed in compliance with row and column series of the registry and cadastral database.

Later on, correlation ties between values of the $\mathrm{TP}_{\mathrm{x}}$ (errors of technical passport layer) and $\mathrm{D}_{\mathrm{y}}$ (division layer errors) have been identified. Usually, in order to observe the correlation between the two connections, expression (1) is used in [1]:

$$
r(x, y)=\frac{n \sum_{i=1}^{n} x y-\sum_{i=1}^{n} x \sum_{i=1}^{n} y}{\sqrt{\left\{n \sum_{i=1}^{n} x^{2}-\left\{\sum_{i=1}^{n} x\right\}^{2}\right\}\left\{\sum_{i=1}^{n} y^{2}-\left\{\sum_{i=1}^{n} y\right\}^{2}\right\}}}
$$

In 2007, two-factor analysis was provided on the results of topological analysis of spatial data that formed from real estate registration. Determination of correlation ties between variable values. As a result of

$$
\frac{n\left(\left\{T P x_{1} D y_{1}\right\}+\cdots+\left\{T P x_{12} D y_{12}\right\}\right)-\left(\left\{T P x_{1}\right\}+\ldots+\left\{T P x_{12}\right\}\right)\left(\left\{D y_{1}\right\}+\ldots+\left\{D y_{12}\right\}\right)}{\sqrt{\left(n\left(\left\{T P x_{1}\right\}^{2}+\ldots+\left\{T P x_{12}\right\}^{2}\right)-\left(\left\{T P x_{1}\right\}+\ldots+\left\{T P x_{n}\right\}\right)^{2}\right)\left(\left\{D y_{1}\right\}^{2}+\ldots+\left\{D y_{12}\right\}^{2}\right)-\left(\left\{D y_{1}\right\}+\ldots+\left\{D y_{12}\right\}\right)^{2}}}
$$

correlation tie of supervisory sequences will be $r^{2}=0.1319, \mathrm{r}=0.36$. Poor connection between supervisory sequences shows the implementation of division operations in technical passport (TP) layer more accurately (Figure 4). The errors observed in TP layer are the result of registration and accounting 
that held on the non-updated topographic maps, that current situation of urban infrastructure was not reflected in this information. In this regard, this type of errors are observed in ECD.

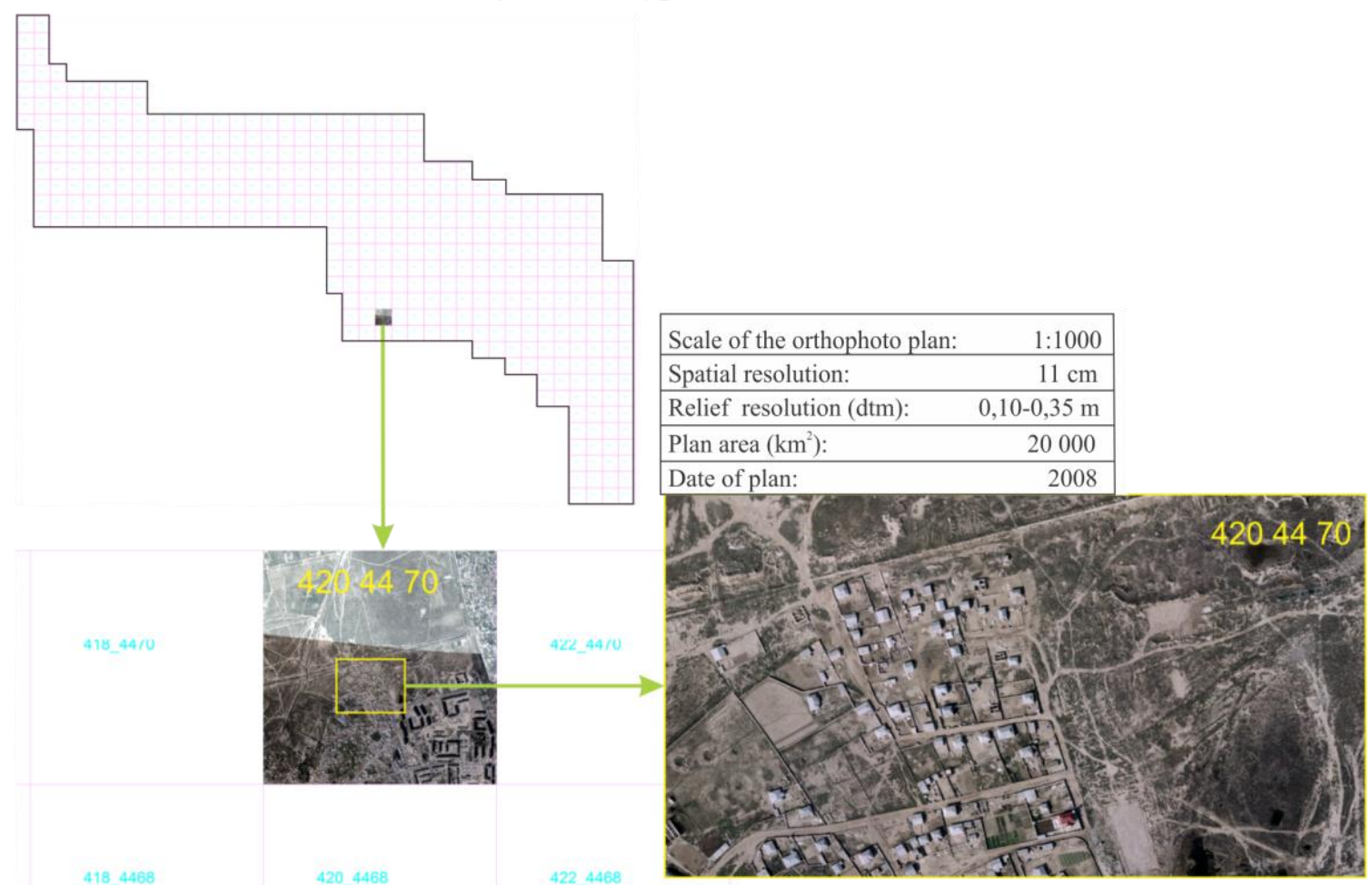

Figure 3. Presentation of a part of the research territory based on orthophoto plan of $11.0 \mathrm{~cm}$ resolution for the year of 2008

Topology conducts analysis on the geometric properties of spatial data. Topological structure of the figures includes their geometry, turning points etc. criteria [2]. Key principle of topological analysis is automatically correcting of errors, that the use of this method is not considered suitable for examined work [3]

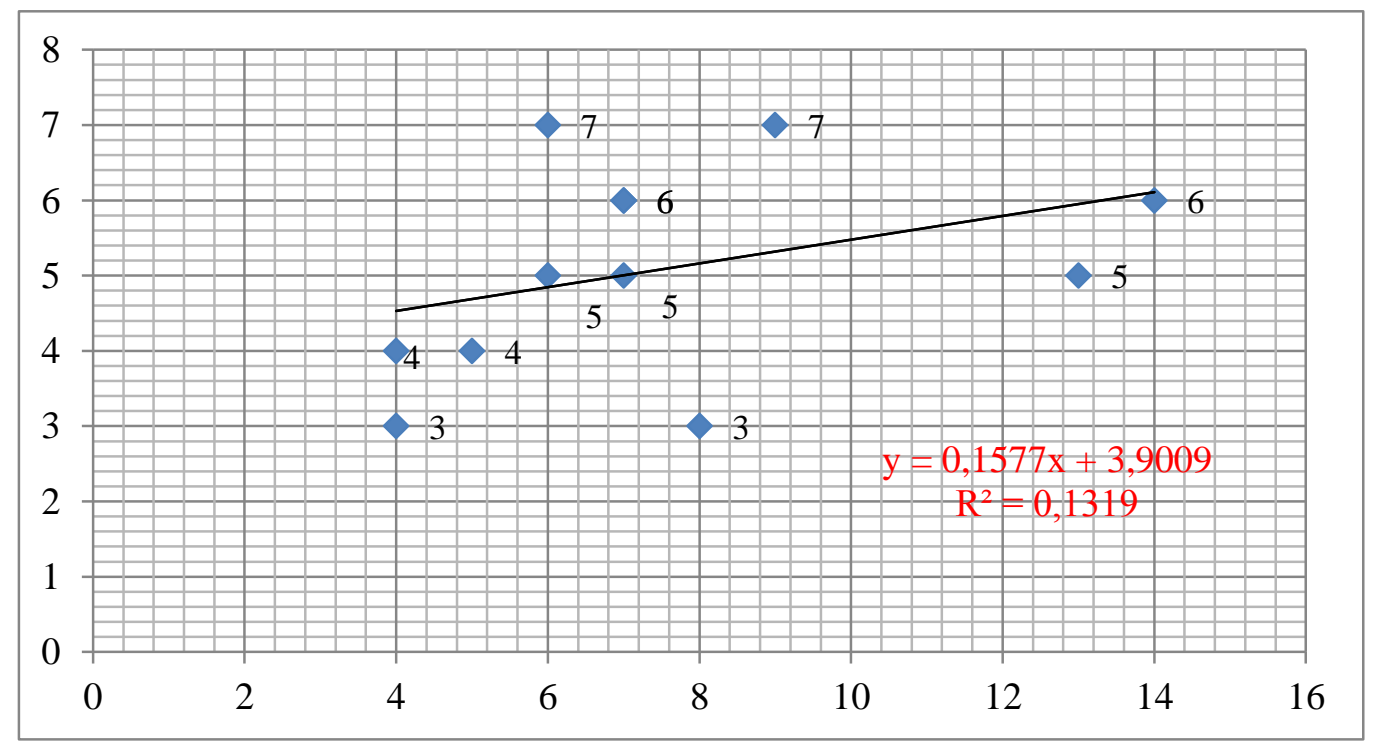

Figure 4. Correlation ties between values of TPx and Dy

In such cases, dependence between variables can be both linear and non-linear. If the problem is of complicated mathematical nature, 2 nd order parabolic equation

$$
y=a_{0}+a_{1} x+a_{2} x^{2}
$$


is used as an attitude equation, 3rd order parabolic equation

in common case $\mathrm{n}$-th order parabolic equation

$$
y=a_{0}+a_{1} x+a_{2} x^{2}+a_{3} x^{3}
$$

$$
y=a_{0}+a_{1} x+a_{2} x^{2}+\cdots+a_{n} x^{n}
$$

Note that, coefficients of non-linear models of pair correlation can also be determined by the method of least squares. In the statement (3) to determine

values of 2 nd order parabolic equation and its $a_{0}, a_{1}$ and $a_{2}$ coefficients, the following equations system can be obtained by means of the least squares method to calculate these ratios:

$$
\left\{\begin{array}{c}
\sum y=N a_{0}+a_{1} \sum x+a_{2} \sum x^{2} \\
\sum y x=a_{0} \sum x+a_{1} \sum x^{2}+a_{2} \sum x^{3} \\
\sum y x^{2}=a_{0} \sum x^{2}+a_{1} \sum x^{3}+a_{2} \sum x^{4}
\end{array}\right.
$$

Sometimes, the values of dependent variable is formed under joint influence of several independent variables $x_{1}, x_{2}, \ldots, x_{n}$. This type of correlation dependencies are of multi-moment correlation dependencies and are reflected through relation equation as in

$$
y=f\left(x_{1}, x_{2}, \ldots, x_{n}\right)
$$

This means that they can be composed of $n$ number for identifying dependence coefficients of topological error factors in ECD.

If dependence between the indexes $y$ and $x_{1}, x_{2}, \ldots, x_{n}$ is linear, then a linear multicorrelation model is used when a linear multi-correlation equation is

$$
y=a_{0}+a_{1} x_{1}+a_{2} x_{2}+\cdots+a_{n} x_{n}
$$

but if dependence is non-linear, in this case, non-linear multi-correlation model is used as

$$
y=a_{0}+a_{1} x_{1}+a_{2} x_{2}^{2}+\cdots+a_{n} x_{n}
$$

Coefficients of both linear and non-linear models of correlations can be identified by the method of least squares.

The article also develops the method of determination of active areas in real estate market (Figure 5), classifies active areas of real estate market over the studied area basing on GIS modules, ortophoto plans and GeoEye-1 data (Figure 6).

Since the data was on a paper during creation of ECD, firstly paper maps had to be digitalized. However, the controversial issues related to width of the area, municipal and SOCAR territories did not allow for application of this method. In such cases, the application of high resolution data becomes urgent, therefore, we focused on the use of orthophotos [4].

While modeling active areas in real estate market, various analysis techniques were parsed for interpolation $Z(s)$ of identification values $s(x, y)$ of the points with known coordinates. Consequently, active areas of the real estate market have been modelled by means of Ordinary Kriging, IDW, radial basis function method, global and local polynomial interpolation methods, trend analysis has been held (Figure 7).

While interpolation through Ordinary Kriging method the following expression is used:

$$
Z(s)=m+e(s)
$$

Here, $s=(X, Y)$ denotes the coordinates of the point; $Z(s)$ - identic index of the point; $m$ - stable average index; $e(s)$ - random errors related to spatial relations.

During the introduction of IDW method of interpolation the calculations are realized as,

$$
\hat{\mathrm{Z}}\left(s_{0}\right)=\sum_{i=1}^{n} \lambda_{i} Z\left(s_{i}\right)
$$


Here, $\hat{\mathrm{Z}}\left(s_{0}\right)$ denotes the index found for the point $s_{0} ; n$ - number of reference points (points around); $\lambda_{i}$-weight for each point used in the model; $e(s)$ - random errors related to spatial relations; $Z\left(s_{i}\right)$ - index measured at the point $s_{i}[6]$.

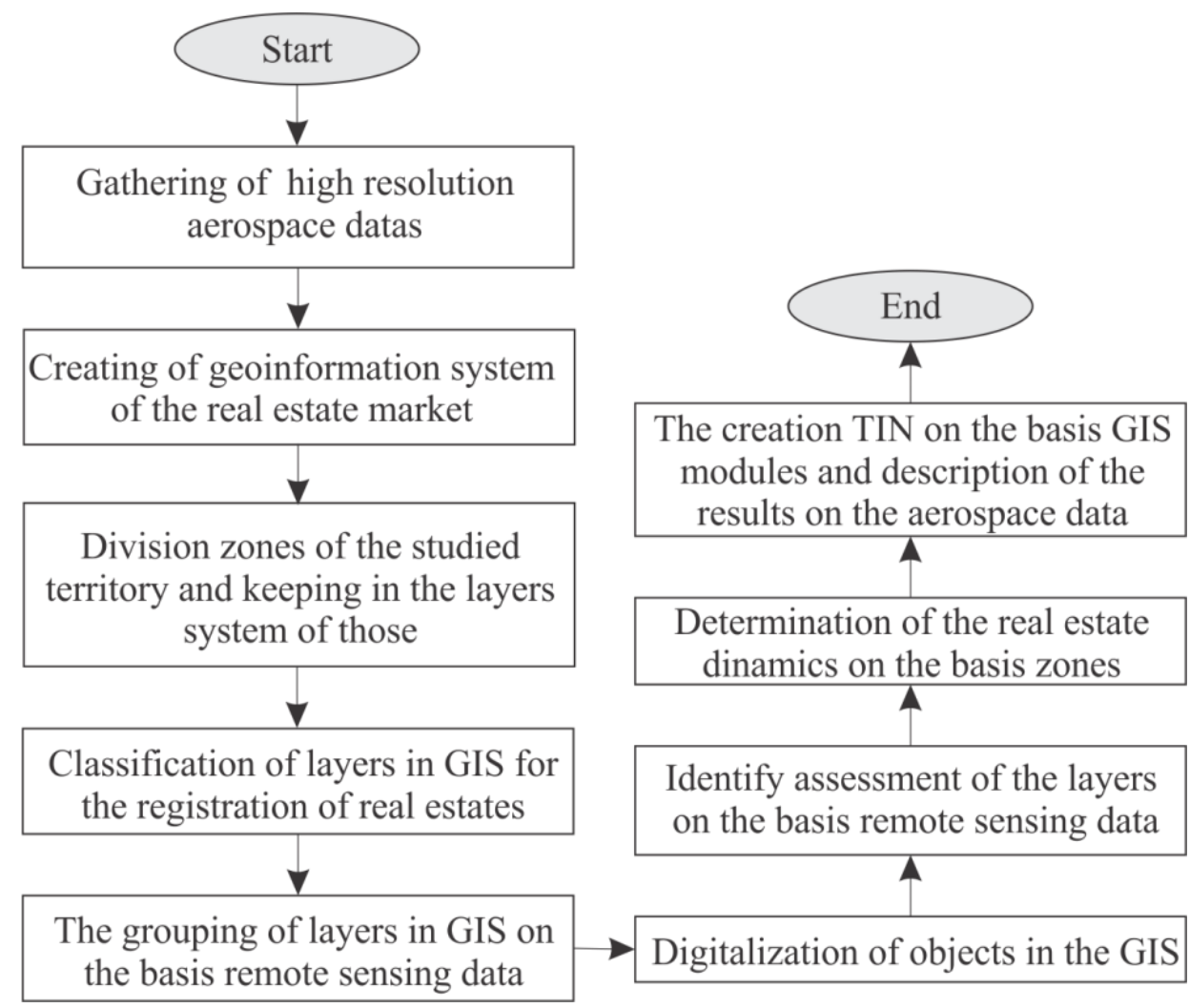

Figure 5. Block scheme of the method of defining the active areas in real estate market
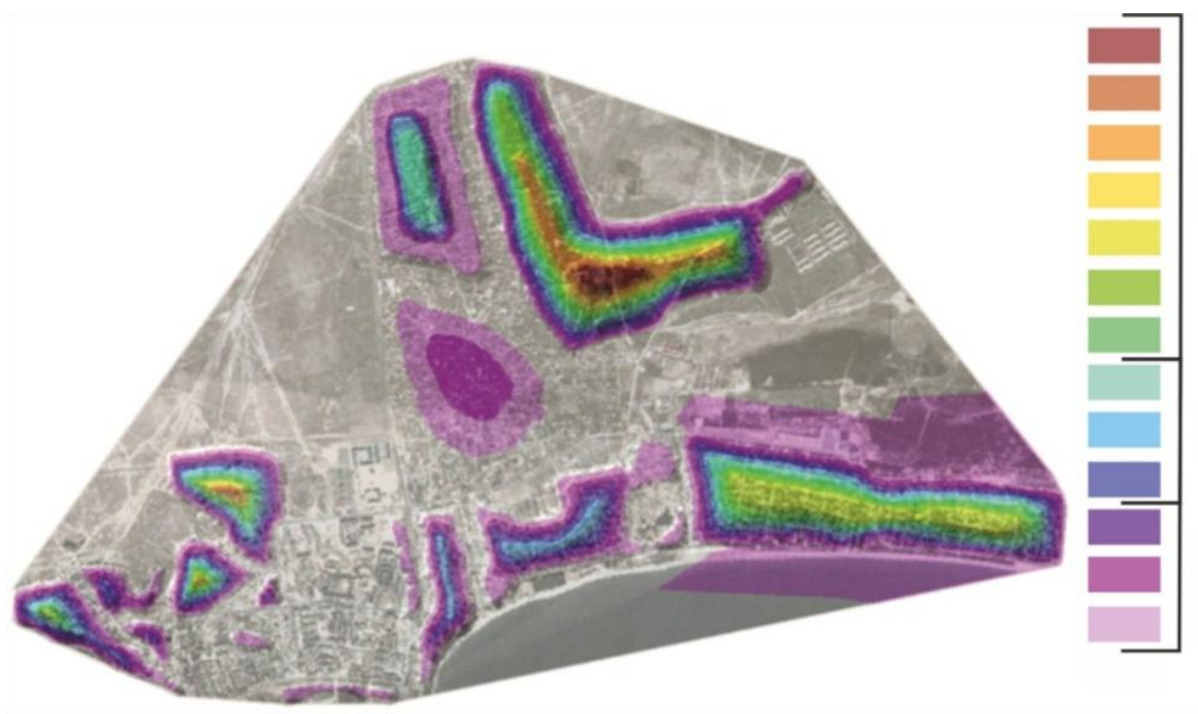

Active $(59,8 \%)$

Relatively active $(21,8 \%)$

Weak $(18,4 \%)$

Figure 6. Classification of the active areas in real estate market in Hovsan district for the years of 2003-2010

Comparative analysis is carried out among dynamics models developed on the basis of various applied interpolation methods in the study (Figure 8), and obtained differences have 
shown that, Kriging method seems more efficient than other methods. Another formula of IDW method is expressed as follows [7]:

$$
\lambda_{i}=\frac{d_{i 0}^{-p}}{\sum_{i=1}^{N} d_{i 0}^{-p}} ; \quad \sum_{i=1}^{N} \lambda_{i}=1(12)
$$

Here, depending on the rate of distance growth, identical value is shrinking according to the coefficient p. $d_{i 0}$ is the distance between the sought point $s_{0}$ and the value $i$ of the reference point $s_{i}$.

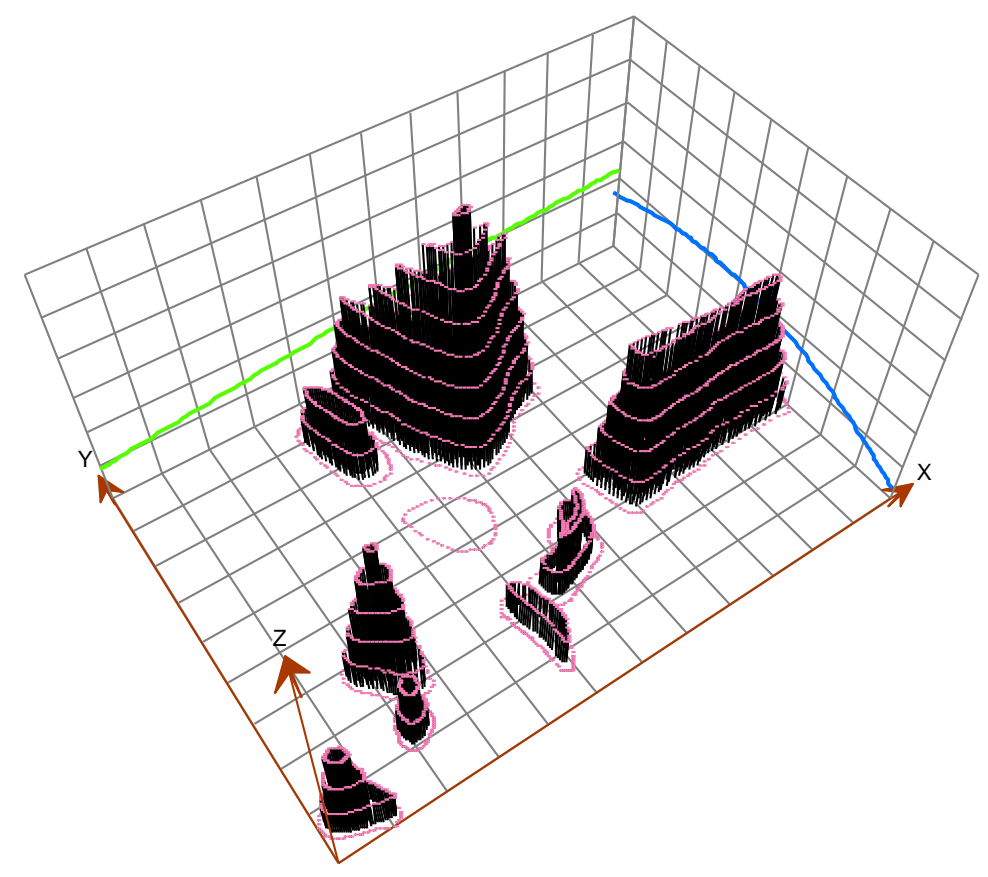

Figure 7. Trend analysis of active areas in real estate market over the subject area basing on Geostatistics module

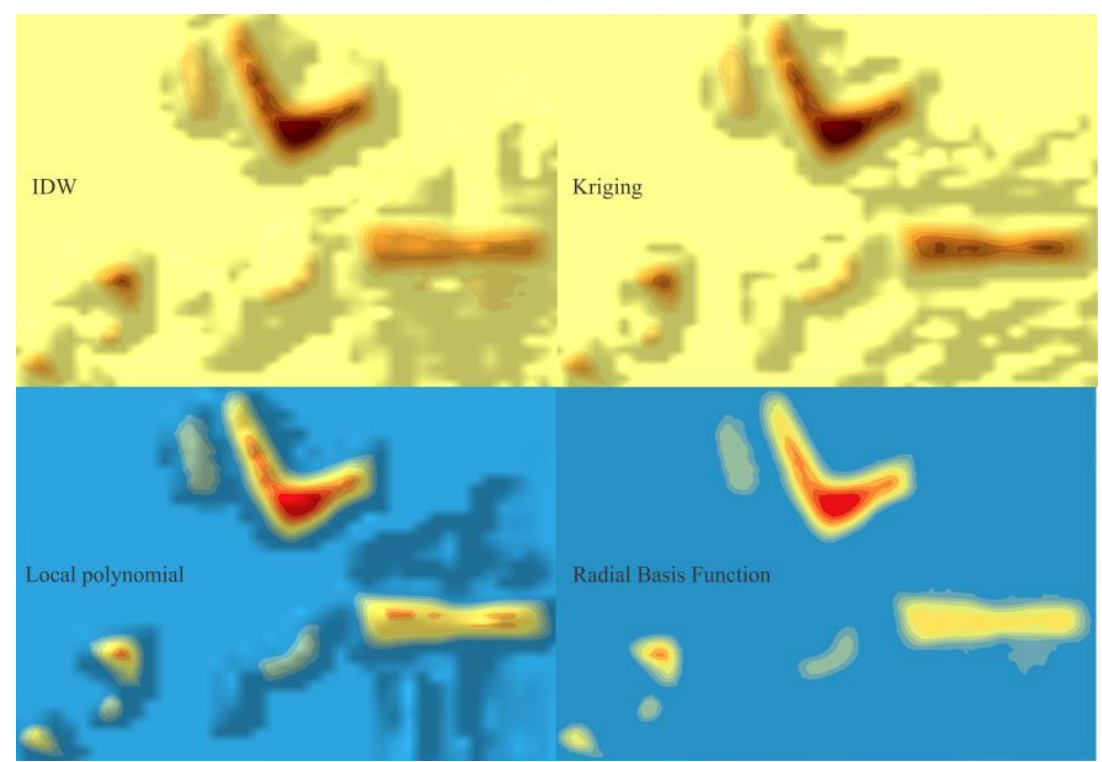

Figure 8. Presentation of the models developed on the basis of various interpolation techniques 
During modeling of real estate market, growth indices CMYK (cyan, magenta, yellow, key color) are measured according to the subtractive scheme (Table 4) [8], and the scale is obtained (Figure 9).

Table 4

Values of color tints for CMYK subtractive scheme during interpolation through ordinary Kriging method

\begin{tabular}{|c|c|c|c|c|c|c|c|c|c|c|}
\hline \multirow{3}{*}{ CMYK } & \multicolumn{10}{|c|}{ Polygons (10) } \\
\cline { 2 - 12 } & $\mathbf{1}$ & $\mathbf{2}$ & $\mathbf{3}$ & $\mathbf{4}$ & $\mathbf{5}$ & $\mathbf{6}$ & $\mathbf{7}$ & $\mathbf{8}$ & $\mathbf{9}$ & $\mathbf{1 0}$ \\
\cline { 2 - 12 } & 0 & 1 & 1 & 3 & 4 & 11 & 23 & 35 & 47 & 58 \\
\hline $\mathrm{C}$ & 0 & 9 & 16 & 24 & 31 & 42 & 57 & 70 & 84 & 100 \\
\hline $\mathrm{M}$ & 50 & 57 & 64 & 72 & 79 & 84 & 89 & 93 & 97 & 100 \\
\hline $\mathrm{Y}$ & 0 & 0 & 0 & 0 & 0 & 0 & 0 & 0 & 0 & 0 \\
\hline
\end{tabular}

Polygons

Min

Figure 9. Scale set up by the values of color tints obtained through Kriging method

The studies show that IDW method seems to be nearest to the Kriging method among interpolation methods for its effective results (Figure 10). According to the models of real estate market dynamics generated on the basis of Geostatistical analysis methods, it is found out that the growth of real estate is more active in the south-west of the settlement, in the east massive of Hovsan village and in Hovsan gardens (Figure 11) [9].

Being characterized by a wide scope, previously GIS was providing geographic data storage, search and description, but was not enable to analyze the spatial data. Currently, GIS has specific capabilities for analyzing spatial data, and its integration can be observed in many areas [10].
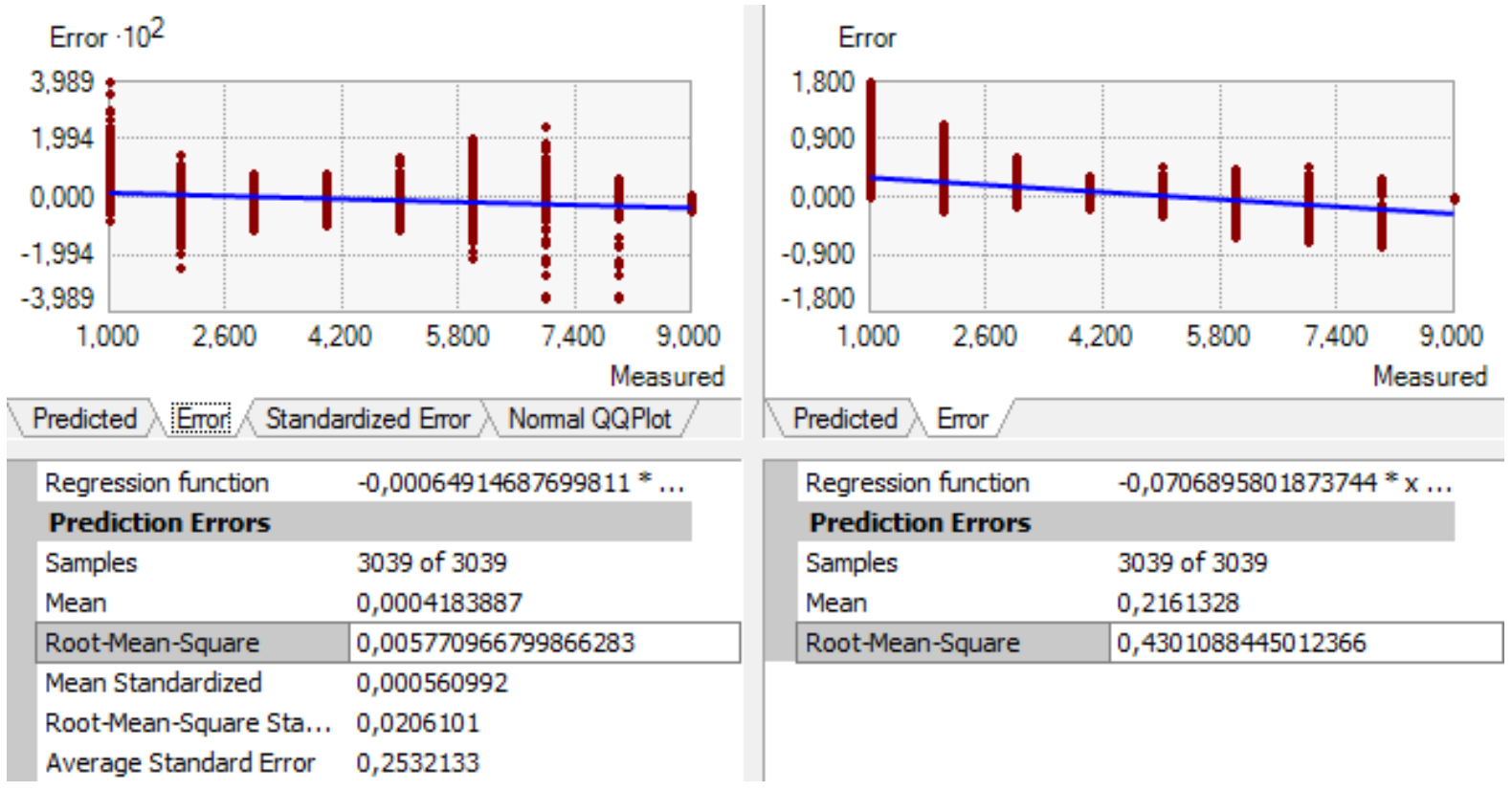

Figure 10. The results of the comparative analysis of the models developed on the basis of IDW and Ordinary Kriging methods in the Geostatistical analysis module of ArcGIS software 
Thus, particularly, studying the real estate market in different periods and identifying active areas in this regard, as well as complex study of the state-of-the-art methods in this field, including forecasting, model development stages have revealed the need for the use of ECD based on different information technologies and aerospace data. Development and state-of-theart of urban infrastructure information system makes it necessary to expand the scope of the information systems usage, and in this case, storage, systematization, update and processing of different types of data comes to the fore.

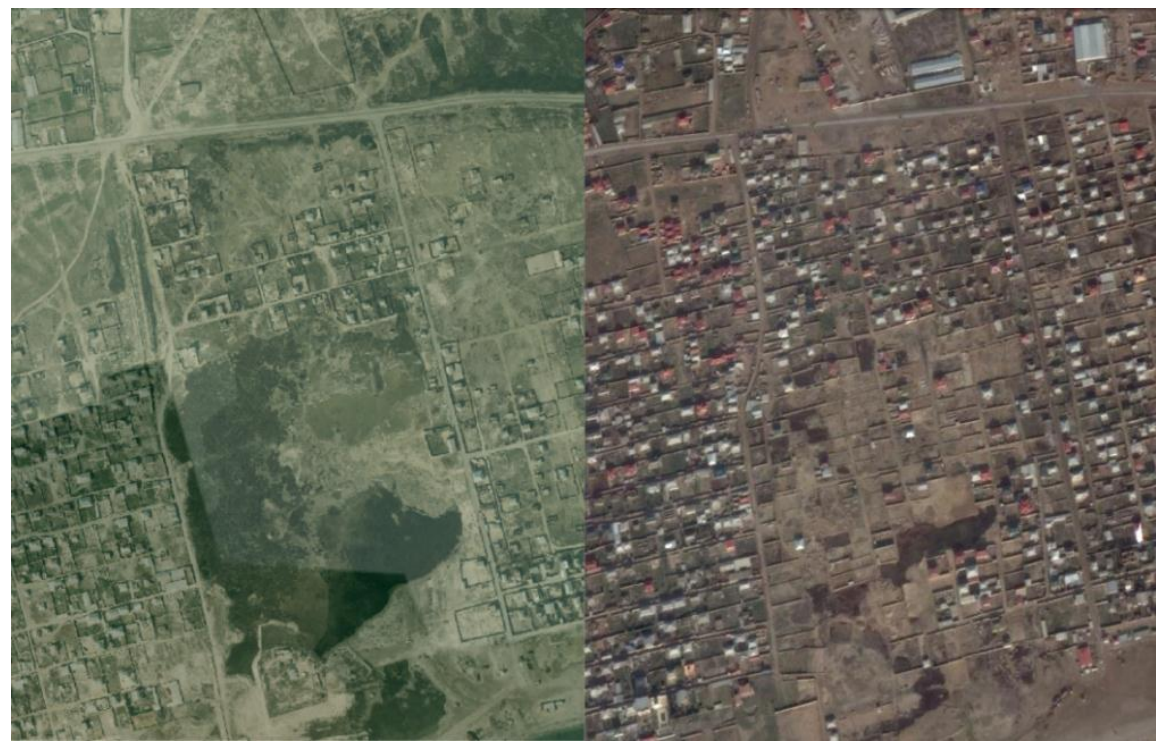

Figure 11. Presentation of dynamics of a portion of Hovsan gardens in aerospace description fragments for the years of 2003 and 2010

\section{Conclusion}

In order to describe expansion tendencies of settlements on the map the topographic planning of territories and updating of the inferences regularly is required. At the same time, there is a need for the application of high resolution aerospace data. Even one of the key problems usually facing in the development of geographic information systems is reflecting the current state of the infrastructure. Because, GIS provides the development of accurate models and implementation of comparative analyses. In this regard, the use of high resolution orthophoto plans reflecting modern state of urban infrastructure elements is appropriate in establishing ECD. The urgency of the study from scientific and practical point of view is substantiated with the fact that, application opportunities of high resolution aerospace data have been investigated, effective outcomes have been achieved basing on GIS analysis modules and mathematical-statistical analysis methods, including by the application of different interpolation methods. Thus, in the given article we have achieved the development of ECD based on high resolution aerospace data in GIS platform; we have carried out topological analysis on spatial data in ECD, detected topological errors according to the existing layer systems, and identified correlation ties between the factors of these errors, and outlined series of mathematical-statistical methods of analysis just as the same way. Moreover, the method of determination has been developed in the active areas of real estate market; active areas in real estate market have been classified over the studied area according to the proposed method. In this regard, different interpolation methods have been analyzed. Comparative analysis of numerous dynamic models developed on the basis of interpolation methods have been conducted, and obtained differences has shown Kriging method to be more efficient than others. 


\section{References}

1. Balyev N.N. determination of the correlation between the aircraft's flight parameters to recover the flight information // Journal of "Information Technology", 2010, No 2, pp.103-108.

2. Ananyev Y.S. Geographic Information System, Tomsk, publishing house TPU, 2003, p.70.

3. David M. Theobald. About the shaping of the coverage. Topology on shaping and shapefiles // ArcUser, April-June 2001.

4. Suleymanov T.I., Aliyev E.M. the creation of an electronic database of the management of spatial facilities based on orthopotos and geographic information system technology // National Aerospace Agency News, 2009, No2 (12), pp.22-28.

5. Demyanov V.V., Savelyev E.A. GEOSTATISTICS. Moscow Science 2010, p. 327.

6. Geostatistical analysis (ArcGIS). User's Guide, "ESRI, Ltd". 2001, p. 278.

7. Aliyev E.M. Mapping the density of the real estate objects in Hovsan settlement of Surakhani district with Hypsometric method and geographic information technology // National Aerospace Agency News, 2011, No 2 (14), pp. 34-41.

8. Aliyev E.M. Studying the dynamics of the real estate market with the geographic information technologies and remote sensing data // Journal of Information Technology, 2012, No 1, pp.61-69.

9. Stewart Fotheringham, Peter Rogerson. Spatial analysis and GIS. "Taylor \& Francis", 1994, 296 p. 